\title{
Drift characteristics of green macroalgae in the Yellow Sea in 2008 and 2010
}

\author{
QIAO FangLi ${ }^{1,2 *}$, WANG GuanSuo ${ }^{1,2}$, LÜ XinGang $^{1,2} \&$ DAI DeJun ${ }^{1,2}$ \\ ${ }^{1}$ The First Institute of Oceanography, State Oceanic Administration, Qingdao 266061, China; \\ ${ }^{2}$ Key Laboratory of Marine Science and Numerical Modeling (MASNUM), State Oceanic Administration, Qingdao 266061, China
}

Received October 9, 2010; accepted May 4, 2011

\begin{abstract}
In order to investigate the aggregation mechanism of green macroalgae (Enteromorpha prolifera) on the Qingdao coastline, the macroalgal drift characteristics in the Yellow Sea during June and July in 2008 and 2010 were simulated using a three-dimensional wave-tide-circulation coupled model. In June 2008, the monthly-mean surface current flowed onshore and its direction was almost perpendicular to the Qingdao coastline, which was identified as the main reason for a huge accumulation of algae in the coastal waters off Qingdao. The current became parallel to the coastline in July 2008; this shift in current direction led to little accumulation of algae near Qingdao and thus relieved the environmental pressure on the Olympic sailing events. By using the coupled model, we predicted that there would be no serious algal accumulation at Qingdao in late June 2010, which was later confirmed by observations. This study demonstrated that the drift path of macroalgae near Qingdao is mainly controlled by the surface current, which is primarily driven by wind. Regional climate change is therefore one of the means by which physical processes affect marine ecosystems.
\end{abstract}

Yellow Sea, macroalgae, Enteromorpha prolifera, drift path, simulation, prediction

Citation: Qiao F L, Wang G S, Lü X G, et al. Drift characteristics of green macroalgae in the Yellow Sea in 2008 and 2010. Chinese Sci Bull, 2011, 56: 2236-2242, doi: 10.1007/s11434-011-4551-7

A massive green tide, caused by a bloom of the alga Enteromorpha prolifera, occurred in June 2008, just before the Olympic sailing events. A large amount of algae accumulated in the coastal waters off Qingdao and covered the Olympic Sailing Arena. Swift scientific measures were implemented at the onset of the green tide [1]. Besides observations from ships and airplanes, remote sensing is another effective means to monitor the spread of drifting macroalgae $[2,3]$. The drifting macroalgae in the Yellow Sea (YS) usually aggregate in a pattern of bands. Satellite images obtained by synthetic aperture radar (SAR) showed that the distance between neighboring bands was $1.0-1.5 \mathrm{~km}$ [4], which is much larger than the distance between convergence lines, typically about 50-100 m, of Langmuir cells

*Corresponding author (email: qiaofl@ fio.org.cn)
[5]. The larger distance was explained by Thorpe [6] as a result of continual combination of Langmuir cells. When SAR images were used to estimate the coverage of floating algae, however, the estimated result might be one order larger than the actual measurement. This is because the floating macroalgae reduces the downwind small-scale surface waves, and the small-scale surface waves are the physical parameter by which SAR monitors the floating macroalgae [4]. From a marine ecosystem view point, the bloom of macroalgae in 2008 could be attributed to the rapid development of marine aquaculture in coastal waters, which provides sufficient nutrients supporting the growth of seaweeds [7]. In terms of a physical view point, the decreased wind speed in the southern YS in recent years could be a key physical factor promoting the bloom of macroalgae. The decreased wind speed reduced the strength of surface waves, which led to a lower concentration of suspended sediments 
in the shallow water along the northern coast of Jiangsu Province. The reduced concentration of suspended sediments made the light conditions more suitable for macroalgal growth [8]. Tide-induced upwelling in the waters near the Subei Bank might be another important physical process fueling excessive growth of the algae [9], owing to its role in carrying nutrients upward from deep water to the euphotic zone.

Many studies of the YS green-tide disaster, including assessment of the related economic loss [10], have been carried out in recent years. However, the amount of research focusing on the ocean's dynamic effects on the macroalgal bloom in the YS is limited. One such study by Lü et al. [11] showed the relationship between the sunken algal aggregation and the convergence of tidal flow velocity. The present study focused on the dynamics of the drift and transport of the floating algae. We analyzed the dynamics of the algal accumulation in coastal waters off Qingdao in June 2008, and predicted whether it would happen again near Qingdao in 2010. In fact, floating algae are a good test organism for examining the performance of numerical ocean models in their ability to simulate ocean circulation and to trace the source of surface-drifting materials, such as algae and radioactive debris, as well as oil spills, in the sea.

\section{Numerical model}

\subsection{Introduction to the numerical model}

A numerical ocean circulation model is a basic tool used to trace the source of green algae and to predict their drift paths. The MASNUM (Key Laboratory of Marine Sciences and Numerical Modeling, State Oceanic Administration) wave-tide-circulation coupled model was used in this study. The ocean component of the coupled model is based on the Princeton Ocean Model (POM; [12,13]), and the wave component is the MASNUM wave model [14,15]. The model domain covers the geographical area $\left(15^{\circ}-41^{\circ} \mathrm{N}\right.$, $\left.105^{\circ}-135^{\circ} \mathrm{E}\right)$ with a horizontal resolution of $(1 / 24)^{\circ} \times(1 / 24)^{\circ}$ and 30 sigma layers in the vertical. Open boundary conditions are provided by the Northwest Pacific model [16], which covers the area $\left(0^{\circ}-50^{\circ} \mathrm{N}, 99^{\circ}-150^{\circ} \mathrm{E}\right)$ and whose grid is $(1 / 8)^{\circ} \times(1 / 8)^{\circ}$. The Northwest Pacific model is nested in a quasi-global model domain covering the area $\left(78^{\circ} \mathrm{S}-\right.$ $\left.65^{\circ} \mathrm{N}, 0^{\circ}-360^{\circ}\right)$ with a horizontal resolution of $(1 / 2)^{\circ} \times(1 / 2)^{\circ}$ [13]. Atmospheric forcing fields of the quasi-global model were obtained from the NCEP reanalysis data (http://www. nco.ncep.noaa.gov/pmb/products/gfs/). The source codes of the POM and MASNUM wave models were recoded using the MPI parallel technique to speed up the calculation [17]. Surface wave-induced mixing [18] was included, and tidal waves were incorporated into the POM by specifying tidal elevation forcing at the open boundary $[9,16]$. Atmospheric forcing fields of the Northwest Pacific model were obtained from 72-h forecasting results of the MM5 model [19], which covers the area $\left(0^{\circ}-50^{\circ} \mathrm{N}, 99^{\circ}-150^{\circ} \mathrm{E}\right)$ with a resolution of $(1 / 5)^{\circ} \times(1 / 5)^{\circ}$ and is operationally run in the National Marine Environmental Forecasting Center (NMEFC) of China [20]. The MASNUM wave-tide-circulation coupled model has been used as part of the operational forecasting system at the NMEFC and the East China Sea Forecasting Center of the State Oceanic Administration of China.

\subsection{Model validation}

Validation of the forecasting system was carried out by comparing simulated and observed currents from a submerged buoy, which was located at $\left(34^{\circ} 00^{\prime} \mathrm{N}, 122^{\circ} 50^{\prime} \mathrm{E}\right)$ with water depth of about $60 \mathrm{~m}$. The current velocity was measured at a time interval of $10 \mathrm{~min}$ from 02:00 on November 25,2008 , to $14: 00$ on January 2,2009 , using a bottom-mounted, upward-looking acoustic Doppler current profiler. Since the time interval of the output of the operational forecasting system is $6 \mathrm{~h}$ (i.e. 02:00, 08:00, 14:00, and 20:00 daily), we reprocessed the observed current data to form a new set with the same 6-h interval for comparison. Results of 24-h forecasts agreed well with the observations, as shown in Figure 1. The correlation coefficient of velocities between numerical forecasts and observations in the upper layer (at $6 \mathrm{~m}$ ) was 0.80 . The root-mean-square errors of the velocity component of $U$ and $V$ were 7.0 and 11.6 $\mathrm{cm} / \mathrm{s}$, respectively; and the corresponding correlation coefficients were 0.86 and 0.93 , respectively. These comparisons show satisfactory performance of the forecasting system in simulating ocean currents at the surface.

\section{Characteristics of the drifting macroalgae in 2008}

Between late May and early July, 2008, the floating algae posed a practical threat to the marine environment of the Olympic Sailing Arena [1]. On May 30, it was reported by aerial surveillances that a large area of green bands had appeared about $140 \mathrm{~km}$ southeast of Qingdao. On June 15, the floating algae began to invade the Qingdao coast from Laoshan to Xuejia Island. The most serious algal invasion on the shoreline occurred after June 20, when the thickness of the algal accumulation was $0.3-0.5 \mathrm{~m}$ on average, and

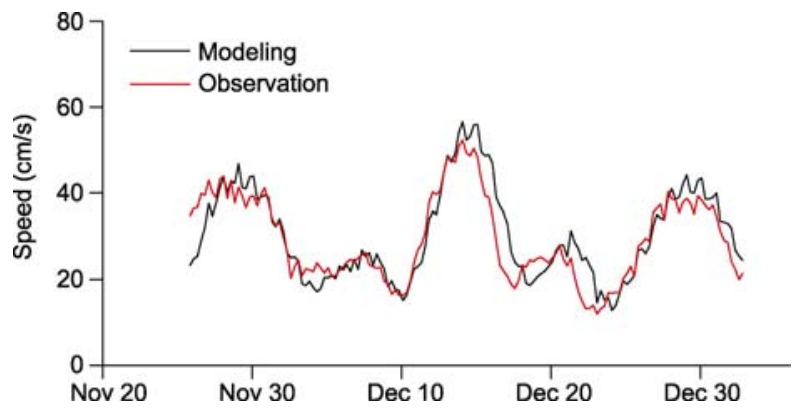

Figure 1 Comparison of current speed between measurements and 24-h forecasts (at 6-m depth) at a fixed point. 
the peak thickness exceeded $1.0 \mathrm{~m}$ near the Zhanqiao Pier. These descriptions of the algal bloom evolution were also revealed by observations from satellite remote sensing (see Figure 1 in [11]), which showed that floating green algae first emerged in late May in the coastal waters of Qingdao, began to aggregate over a large area on about June 22, and bloomed on about June 28, 2008. The local government organized more than 1800 fishing and transportation vessels and 20000 people to continuously clean up the algae. Approximately 0.8 million fresh-weight tons of algae were removed from the beaches and nearby coastal waters. The floating algae gradually became invisible in July.

From the view point of ocean dynamics, two questions could be asked. Why did the floating algae aggregate in Qingdao in June? What were the dynamic reasons behind the relatively quick reduction of algae in early July?

Since algae float at the sea surface, their movement should be directly affected by the sea-surface current. To answer the above questions, we numerically modeled the surface ocean circulation in June 2008 using the MASNUM coupled model. Figure 2(a) reveals that the monthly-mean surface current was northwestward, almost perpendicular to the coastline of Qingdao that runs from the northeast to the southwest. Thus the direction of the surface current was favorable for the onshore transport of algae. The surface flow velocity was $0.1-0.2 \mathrm{~m} / \mathrm{s}$, corresponding to a drift speed of $8-16 \mathrm{~km} / \mathrm{d}$. According to this estimation, the algae would land on Qingdao beaches in mid-June, which agrees with the actual landing date of June 15 . The sea-surface temperature (SST) off Qingdao was about $18^{\circ} \mathrm{C}$, which was suitable for the growth of E. prolifera. We note that the drift velocity of algae might not be exactly the same as the ocean current speed, and the relationship needs further study. Nevertheless, the above analyses show that the surface flow direction, which was perpendicular to the coastline, was likely to be the main dynamic cause of the massive algal aggregation in Qingdao in June, 2008.
The mean surface current in the first 10 days of July 2008 is shown in Figure 2(b). It shows a significant difference from Figure 2(a) in terms of the flow direction off Qingdao, which is mainly northeastward and almost parallel to the coastline. Consequently, the algal mass in the open sea would not progress steadily toward the beach, notwithstanding small amounts of algae still affecting the Olympic Sailing Arena. We believe that the fundamental reason, from the view point of ocean dynamics, for the sudden alleviation of algae removing pressure on the area in July was the shift in surface current direction, which became almost parallel to the coastline and hindered the onshore transport of the algae. The sinking [11] and mechanical removal of algae certainly helped in the clean-up process.

\section{Modeling and forecasting of the algal bloom in 2010}

The green tide again broke out in 2010 in the YS, the evolution of which can be depicted by the observed Moderate Resolution Imaging Spectroradiometer (MODIS) ocean color images. Observation by MODIS is limited to cloud-free conditions, so we selected four images (Figure 3), in which the algal distribution in the YS is not severely affected by clouds. The images were obtained from the daily products of the MODIS Rapid Response System of NOAA (http:// rapidfire.sci.gsfc.nasa.gov/). Occurrence of green algae was first detected about $1.5^{\circ}$ south of Qingdao in early June, 2010, when the algal coverage was very small (Figure 3(a)). The YS was covered by thick clouds on most days in mid-June but, as shown in Figure 3(b) and (c), the algal coverage quickly expanded in late June into a " $\Gamma$ " shape. On July 6, the distribution of algae had become T-shaped. Based on the satellite observations, the amount of green macroalgae in Qingdao coastal waters was less than that in 2008 [11].
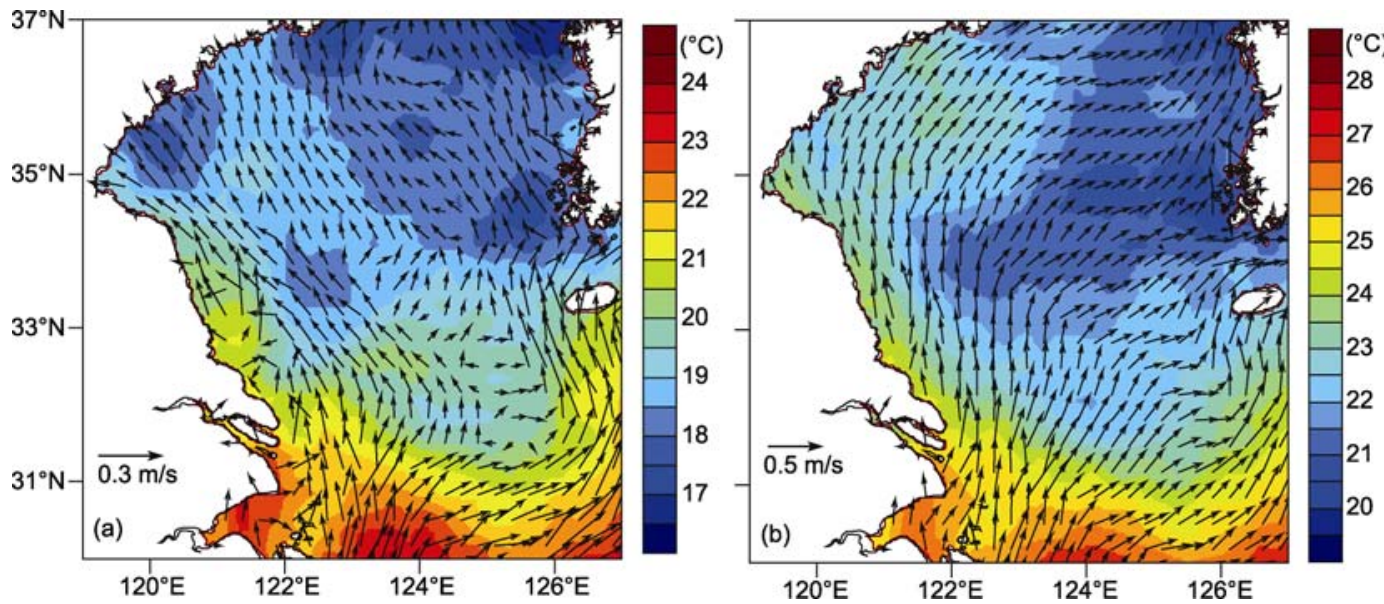

Figure 2 Simulated sea-surface current and sea-surface temperature fields. (a) Monthly mean in June, 2008; (b) ten-day mean during July 1-10, 2008. 

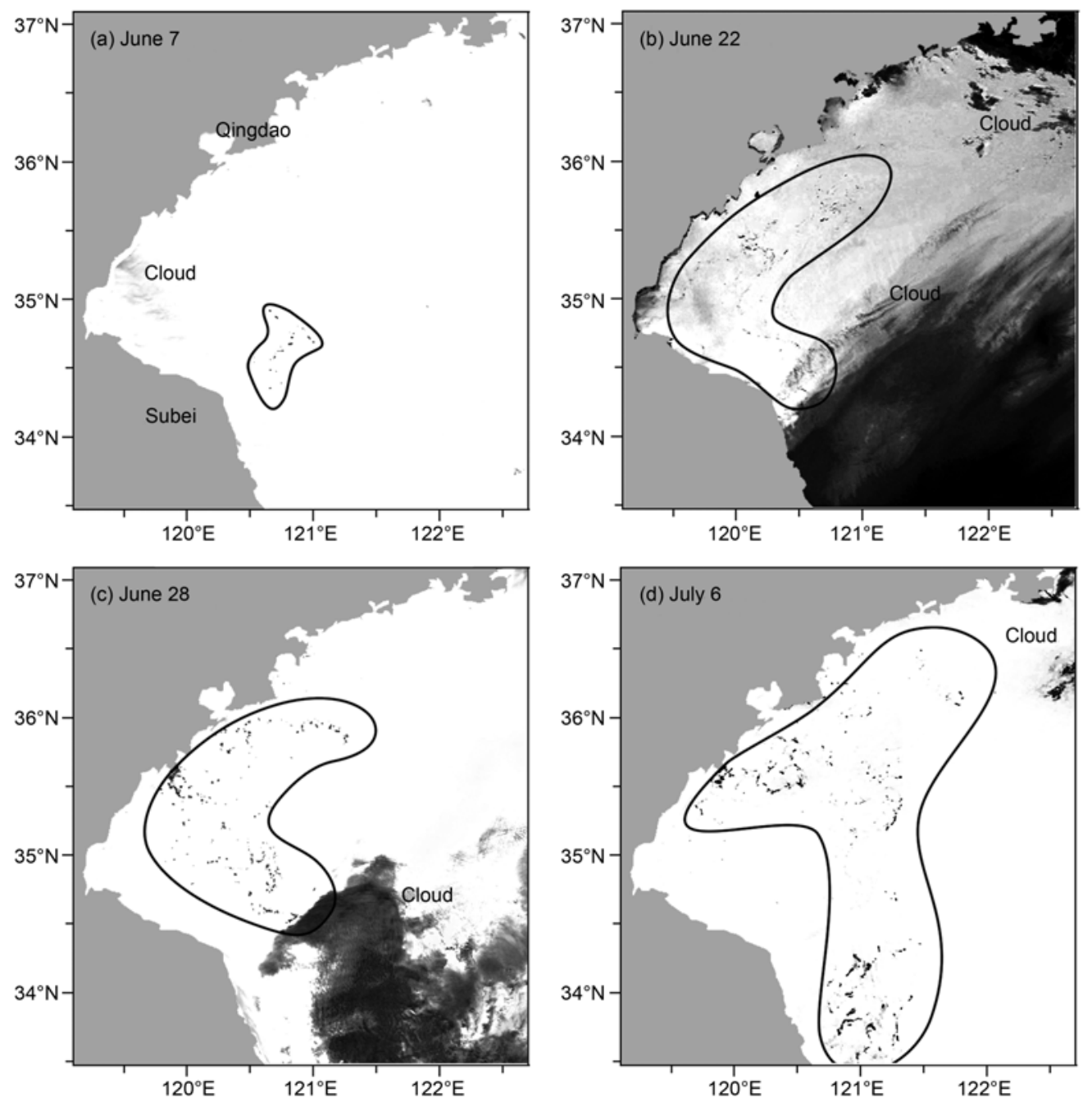

Figure 3 Distribution and evolution of green macroalgae in the Yellow Sea in 2010. The area of algal coverage is marked by a black line. These images are edited versions of the false-color satellite images taken from http://rapidfire.sci.gsfc.nasa.gov/.

The modeled sea-surface current and SST fields averaged over 10 days in June and July are presented in Figure 4. The SST rose gradually from June to July. Generally, the surface current was parallel to the coast except during the first 10 days in June. On June 24, the floating algae loomed near Dagong Island (less than $10 \mathrm{~km}$ away from the island), and the municipal government of Qingdao commissioned our research team to predict the future evolution of the algal bloom. On the basis of numerical simulation (Figure 4(a), (b)), we issued a preliminary forecast as follows: provided that no strong easterly wind anomaly occurred, the body of algae will not reach Qingdao; the algae will drift northeastward along the coast with slight influence on the waters south of Jiaonan. The algal surveillance confirmed this forecast. On June 29, our second prediction sustained our initial prediction on June 24. The surface current in early July was almost parallel to the coastline (Figure 4(d)). The distribution features revealed by satellite images (Figure 3 ) are also consistent with the model-predicted circulation pattern.

\section{Interannual variation and mechanism of drifting green algae}

Xia et al. [16] reported the three-layer structure of the summer circulation in the YS. The surface layer $(0-4 \mathrm{~m})$ is sensitive to wind forcing; the middle layer $(5-40 \mathrm{~m})$ is dominated by a basin-scale cyclonic gyre, which is believed to be a typical feature of the YS Cold Water Mass (YSCWM); in the bottom layer (below $40 \mathrm{~m}$ ) a weak southward current exists along the YS trough, and the water in the frontal zone moves away from the fronts toward the shore, in the form of divergent weak currents.

In comparison with 2008 , the monthly-mean wind direction in June 2010 showed deflection toward the right, which caused a similar deflection of the surface current (Figure 5(a)). The surface current in June 2010 was northeastward, while the flow in 2008 was northwestward; therefore, the algae would likely not land on the beach of Qingdao. This 

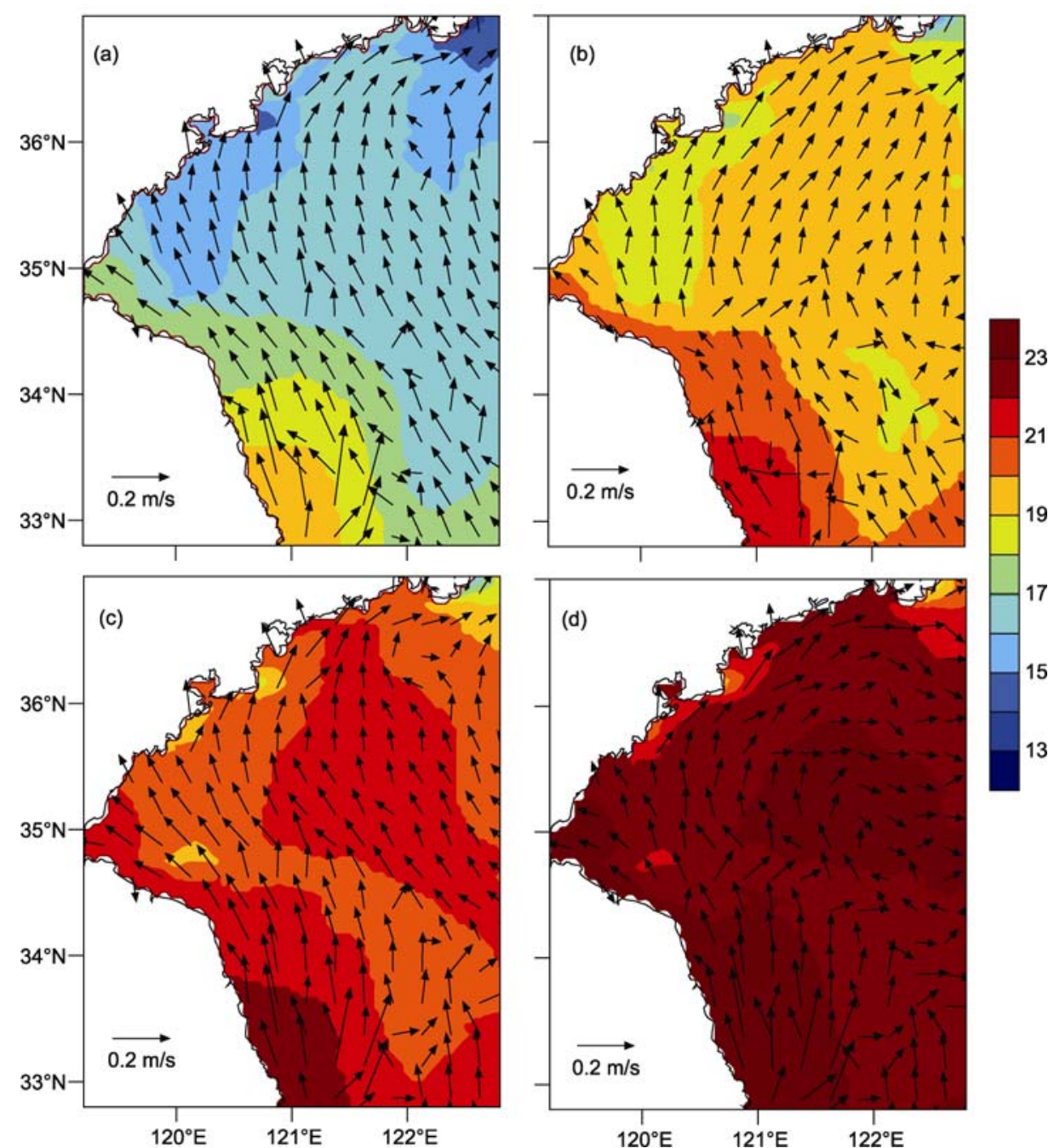

Figure 4 Simulated sea-surface current and sea-surface temperature fields averaged over 10 days in 2010. (a) June 1-10; (b) June 11-20; (c) June 21-30; (d) July 1-10.
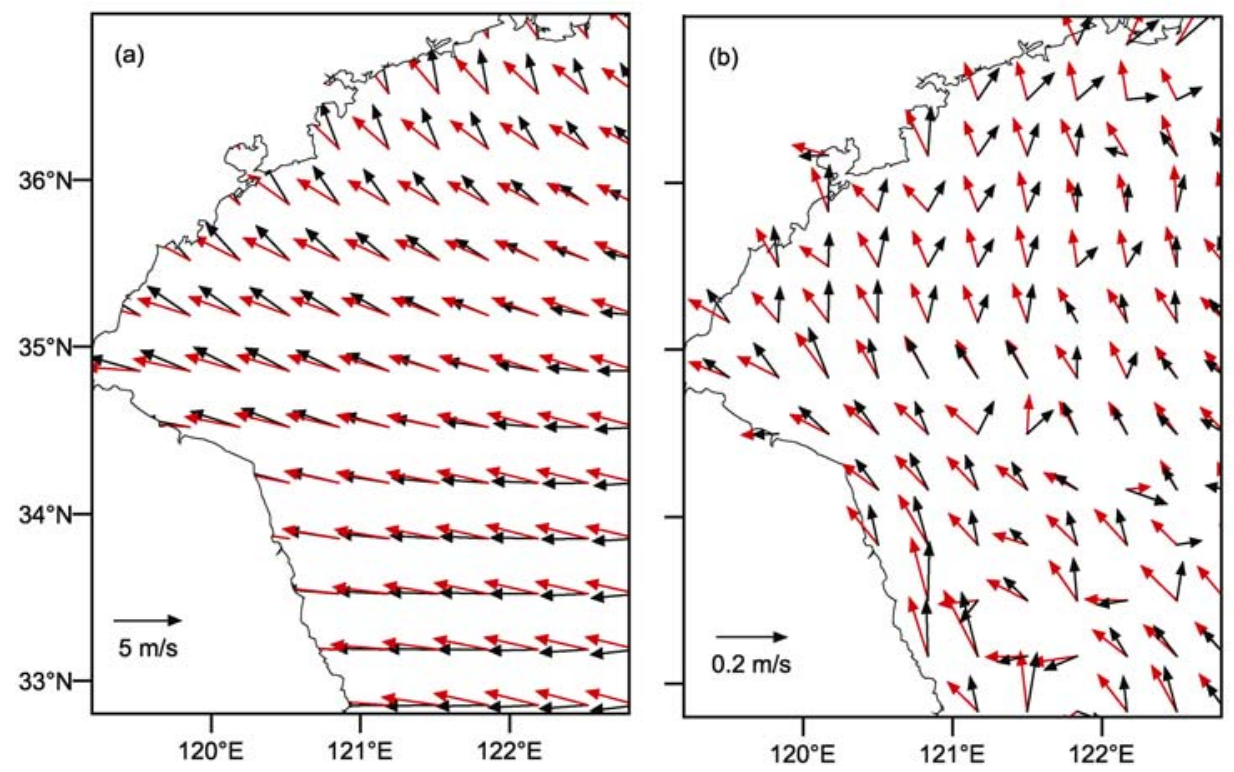

Figure 5 Comparison of wind and current fields in June of 2008 and 2010. Red and black vectors denote 2008 and 2010 values, respectively. (a) Monthlymean wind; (b) monthly-mean surface currents. 
study shows that regional climate variation may influence the marine ecosystem.

The wind and surface current in July in 2008 and 2010 (Figure 6) further supported the hypotheses of this study, i.e. the current along Qingdao's shoreline prevents the algae from landing on the beach in July. A characteristic of the Subei Coastal Current (SCC) is noticeable: it flowed northwestward unanimously in June (Figure 5(b)), whereas it flowed northeastward at $34.5^{\circ} \mathrm{N}$ in July 2010 (Figure 6(b)). This characteristic fits roughly with the change in distribution of the algae from $\Gamma$-shaped to T-shaped (Figure 3(d)).

Because algae usually float at the sea surface, the model performance in simulating sea-surface (or upper-layer) currents is crucial to the prediction of algal drift path. Figure 1 shows the model capacity at a fixed point. Figures 5 and 6 clearly show that the surface ocean flow has the typical features of Ekman drift. On the basis of numerical forecast results with the MASNUM coupled model, we calculated the deflection angle between wind and current directions in the region $\left(119.2^{\circ}-122.0^{\circ} \mathrm{E}, 35.0^{\circ}-37.0^{\circ} \mathrm{N}\right)$ in the southern YS where algal blooms often occur. The average direction of the wind in June 2008 was $118.2^{\circ}$ (meaning the wind blows from southeast toward northwest), and the sea-surface current moved at a $34.3^{\circ}$ angle to the right of the wind; in July 2008, the prevailing wind was $178.6^{\circ}$ and the current deflection was $42.9^{\circ}$. The modeled ocean current unanimously flowed to the right of the wind, and the deflection angle was close to the theoretical angle $\left(45^{\circ}\right)$ of Ekman's theory. Thus, it can be concluded that wind data are critical to forecast algal drift. $\mathrm{Li}$ [21] suggested, through analysis of buoy data, the SCC is basically dominated by wind forcing in summer, so the variation in wind velocity and direction may alter the transport of algae. The conclusion of this paper supports Li's study.

Besides Ekman drift, Langmuir circulation is another important process, though at a much smaller scale, in the upper layer of the ocean. The distance between neighboring algal bands in the YS, estimated from satellite images, ranges from hundreds to thousands of meters [4], which is much larger than the typical distance between the convergence lines of Langmuir cells. Thorpe [6] developed a simple theory, which argued that continual combination of Langmuir cells can result in the formation of observed algal bands. Langmuir circulation is a process affecting the bandtype distribution of floating algae or other materials. As far as the horizontal transport mechanism is concerned, it is forced by the large-scale circulation.

The SCC produced by the model is northward in this study, which implies that we should re-examine the properties of the SCC. Guo and Xu [22] suggested that the SCC flows southward all year round. From schematic diagrams presented by different researchers, it can be roughly discerned that the SCC flows southward [21-23]. However, these schematic drawings are usually concerned with subsurface circulation, rather than the detailed structure of the currents in Subei shallow waters (especially shallower than $30 \mathrm{~m}$ ). The present study, as well as two previous studies $[21,23]$, suggests the coastal current off Subei and Lunan is driven by southerly wind and flows northward in summer. Our numerical modeling based on realistic topography and climatological forcing also shows that, at least in the Subei Bank south of $34.5^{\circ} \mathrm{N}$, the current was northward from the surface to the sea bed, and the subsurface current deeper than the 40-m isobath was the southward branch of the
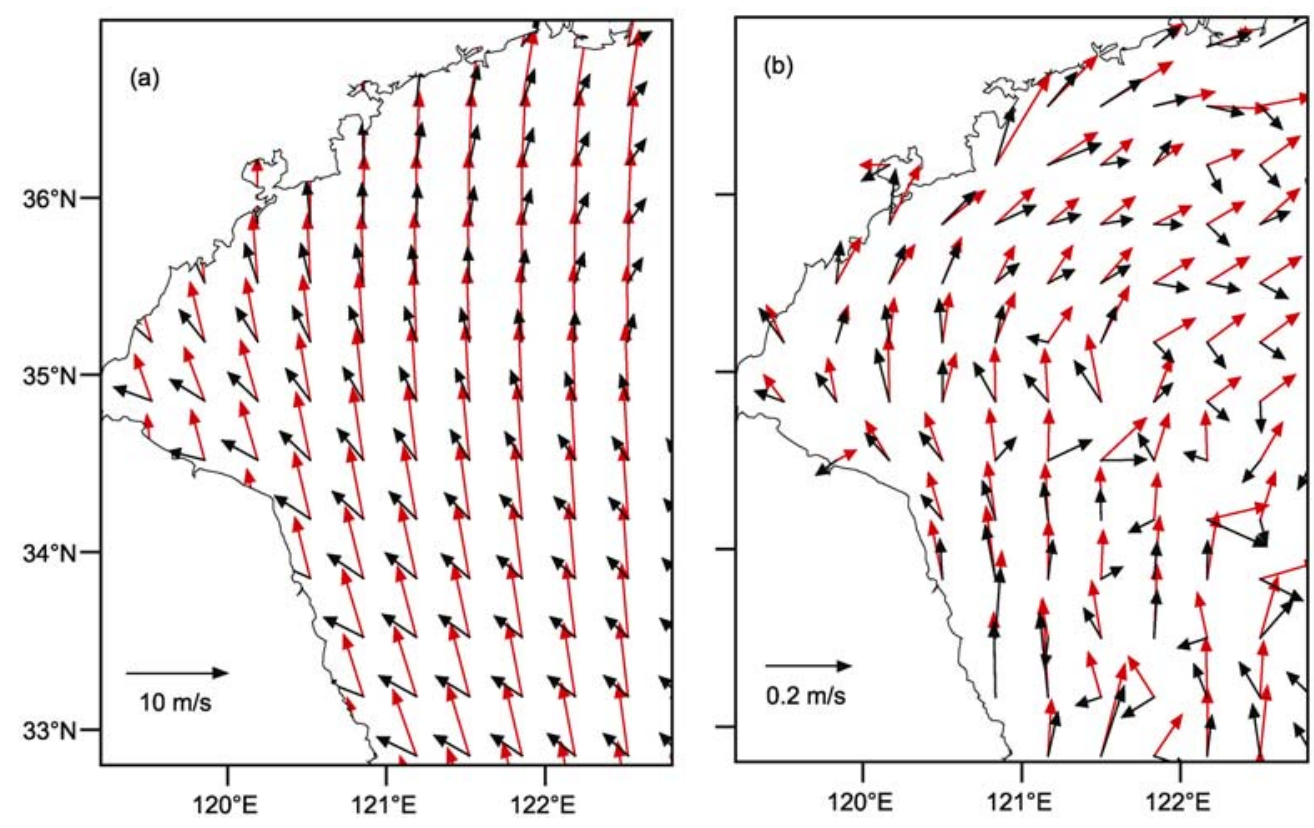

Figure 6 Comparison of wind and current fields in July of 2008 and 2010. Red and black vectors denote 2008 and 2010 values, respectively. (a) Wind field averaged over July 1-10; (b) surface current field averaged over July 1-10. 
YSCWM circulation [16,24]. It will be necessary to redefine the SCC in more detail, e.g. to distinguish the probable different flows separated by the $30-40 \mathrm{~m}$ isobath.

\section{Conclusions}

The surface current in the YS was simulated and forecasted using a high-resolution wave-tide-circulation coupled model. The simulated circulation was characterized by an Ekman drift current. The coastal current off Subei and Lunan was northward. The interannual variation of wind had direct influences on the surface circulation in the YS. In 2010, the weak eastward component of the wind field in June and early July resulted in an evident deflection of the surface flow to the right. The surface current direction in June 2008 was almost perpendicular to the Qingdao coastline, while approximately parallel to the coastline in June 2010.

Carried by the onshore surface current, a large amount of floating algae reached the Qingdao coast and piled up on the beaches in June 2008. The current direction became parallel to the coast in July, and was the main reason for the sudden decrease in algal accumulation in July 2008. In June and July, 2010, the surface current off Qingdao flowed parallel to the coastline; therefore the main algal mass did not reach the shore near Qingdao.

This work was supported by the National 908 Project of China (90802-01-04) and the National Key Technology R\&D Special Program (2008 BAC49B02).

1 Qiao F L, Ma D Y, Zhu M Y, et al. The green marcoalgal bloom in the Yellow Sea in 2008 and the scientific countmeasures (in Chinese). Adv Mar Sci, 2008, 26: 409-410

$2 \mathrm{Hu} \mathrm{C} \mathrm{M,} \mathrm{He} \mathrm{M} \mathrm{X.} \mathrm{Origin} \mathrm{and} \mathrm{offshore} \mathrm{extent} \mathrm{of} \mathrm{floating} \mathrm{algae} \mathrm{in}$ Olympic sailing area. Eos Trans AGU, 2008, 89: 302-303

$3 \mathrm{Hu} \mathrm{C} \mathrm{M}$. A novel ocean color index to detect floating algae in the global oceans. Remote Sens Environ, 2009, 113: 2118-2129

4 Qiao F L, Dai D J, Simpson J, et al. Banded structure of drifting macroalgae. Mar Pollut Bull, 2009, 58: 1792-1795

5 Langmuir I. Surface motion of water induced by wind. Science, 1938, 87: 119-123

6 Thorpe S A. Spreading of floating particles by Langmuir circulation. Mar Pollut Bull, 2009, 58: 1787-1791

$7 \mathrm{Hu}$ C M, Li D Q, Chen C S, et al. On the recurrent Ulva prolifera blooms in the Yellow Sea and East China Sea. J Geophys Res, 2010, 115: C05017, doi: $10.1029 / 2009 J C 005561$
8 Wang X H, Qiao F L, Lu J, et al. The turbidity maxima of the northern Jiangsu shoal-water in the Yellow Sea, China. Estua Coastal Shelf Sci, 2010, doi: 10.1016/j.ecss.2010.10.020

9 Lü X G, Qiao F L, Xia C S, et al. Upwelling and surface cold patches in the Yellow Sea in summer: Effects of tidal mixing on the vertical circulation. Cont Shelf Res, 2010, 30: 620-632

10 Wang X H, Li L, Bao X, et al. Economic cost of an algae bloom cleanup in China's 2008 Olympic Sailing Venue. Eos Amer Geophys Union Trans, 2009, 90: 238-239

11 Lü X G, Qiao F L. Distribution of sunken macroalgae against the background of tidal circulation in the coastal waters of Qingdao, China, in summer 2008. Geophys Res Lett, 2008, 35: L23614, doi:10.1029/2008GL036084

12 Blumberg A F, Mellor G L. A description of a three-dimensional coastal ocean circulation model. In: Heaps N S, ed. Three Dimensional Coastal Ocean Models, Vol 4. Washington D C: American Geophysical Union, 2010. 1-16

13 Xia C S, Qiao F L, Zhang Q H, et al. Numerical modeling of the quasi-global ocean circulation based on POM. J Hydrodyn Ser B, 2004, 16: 537-543

14 Yuan Y L, Pan Z D, Hua F, et al. LAGFD-WAM numerical wave model-I. Basic physical model. Acta Oceanol Sin, 1991, 10: 483-488

15 Yang Y Z, Qiao F L, Zhao W, et al. MASNUM ocean wave numerical model in spherical coordinates and its application (in Chinese). Acta Oceanol Sin, 2005, 27: 1-7

16 Xia C S, Qiao F L, Yang Y Z, et al. Three-dimensional structure of the summertime circulation in the Yellow Sea from a wave-tide-circulation coupled model. J Geophys Res, 2006, 111: C11S03, doi: 10.1029/2005JC003218

17 Wang G S, Qiao F L, Xia C S. Parallelization of a coupled wavecirculation model and its application. Ocean Dyn, 2010, 60: 331-339

18 Qiao F L, Yuan Y L, Yang Y Z, et al. Wave-induced mixing in the upper ocean: Distribution and application in a global ocean circulation model. Geophys Res Lett, 2004, 31: L11303, doi: 10.1029/2004 GL019824

19 Grell G A, Dudhia J, Stauffed D R. A description of the fifth-generation Penn State/NCAR mesoscale model (MM5). NCAR Tech Note, 1995

20 Lin T J, Zhang Y F, Yang X L, et al. The application of MM5 model to predict sea surface wind field (in Chinese). Mar Forecasts, 2004, 21: $1-9$

$21 \mathrm{Li} \mathrm{Y}$. The characteristics and dynamical mechanism of the summertime circulation in East China Sea (in Chinese). Dissertation for the Doctoral Degree. Qingdao: The Institute of Oceanology, CAS, 2010. $1-114$

22 Guo B H, Xu J P. The circulation in China adjacent seas. In: The Oceanography of China Adjacent Seas (in Chinese). Beijing: China Ocean Press, 2005. 174-181

23 Liu Z L, Hu D X. Preliminary study on the Huanghai Sea coastal current and its relationship with local wind in summer (in Chinese). Acta Oceanol Sin, 2009, 31: 1-7

24 Lü X G. A numerical study on the mechanisms of the upwelling in the Yellow Sea and East China Sea (in Chinese). Dissertation for the Doctoral Degree. Qingdao: The Institute of Oceanology, CAS, 2010: $1-147$

Open Access This article is distributed under the terms of the Creative Commons Attribution License which permits any use, distribution, and reproduction in any medium, provided the original author(s) and source are credited. 